\title{
PERANCANGAN APLIKASI CUSTOMER RELATIONSHIP MANAGEMENT (CRM) UNTUK MENINGKATKAN LAYANAN PELANGGAN PADA TOKO LUSI ANA GORDEN LUBUK ALUNG BERBASIS WEB DENGAN MENGGUNAKAN PHP DAN MYSQL
}

\author{
Ainul Mardiah, Jufriadif Na'am, Hezy Kurnia \\ Universitas Putra Indonesia, Padang \\ email:hezykurnia@gmail.com
}

\begin{abstract}
ABSTRAK
Suatu penelitian telah dilakukan pada Toko Lusi Ana Gorden. Mengenai pembangunan Aplikasi Customer Relationship Management (CRM) dengan penggunaan website. Customer Relationship Management (CRM) merupakan salah satu jenis manajemen yang secara khusus membahas teori mengenai penanganan hubungan antara perusahaan dengan pelanggannya dengan tujuan meningkatkan nilai perusahaan di mata para pelanggannya. Saat ini banyak perusahaan yang memanfaatkan Customer Relationship Management (CRM) untuk menjalin hubungan dengan pelanggan.
\end{abstract}

Kata kunci: CRM, Kepuasan Pelanggan, Php, CRM Toko Lusi Ana Gorden, Web.

\section{PENDAHULUAN}

Toko Lusi Ana Gorden adalah salah satu usaha yang bergerak di bidang interior yang memiliki banyak pelanggan. Saat ini masih baru dikenal oleh pelanggan yang berada di disekitar wilayah toko tersebut berada. Untuk peningkatan, maka perlu Toko Lusi Ana Gorden memperkenalkan tokonya ke wilayah yang lebih luas. Tujuan untuk memperkenalkan ke kelayak umum adalah untuk meraih pelanggan yang lebih banyak sehingga meningkatkan penjualan perusahaan dan secara otomatis keuntungan akan bertambah. Dengan sistem yang akan dikembangkan ini, Toko Lusi Ana Gorden mampu berkembang dengan baik sehingga dapat membuka cabang dan menciptakan lapangan pekerjaan yang baru. Berbagai upaya dilakukan untuk tetap mempertahan kelancaran usahanya dan meningkatkan omset usaha, karena, semakin banyak pelanggan pertanda usaha tersebut semakin berkembang dengan baik.Salah satu konsep yang ditawarkan sekarang ini adalah Customer Relationship Management.

Berdasarkan alasan tersebut, penulis tertarik untuk mencoba membuat suatu aplikasi, khususnya pada peningkatan layanan pelanggan dimana aplikasi tersebut menggunakan pengetahuan komputer di bidang Web yang sekiranya dapat mengatasi hal-hal tersebut dan juga dapat digunakan sebagai penunjang dalam meningkatkan layanan kepada pelanggan.

\section{LANDSAN TEORI}

\subsection{Pengertian Sistem Informasi}

Sistem informasi merupakan gabungan dari empat bagian utama. Keempat bagian utama tersebut mencakup perangkat lunak (software), perangkat keras (hardware), infrastruktur dan Sumber Daya Manusia (SDM) yang terlatih. Berikut adalah komponen-komponen pada sistem informasi : 


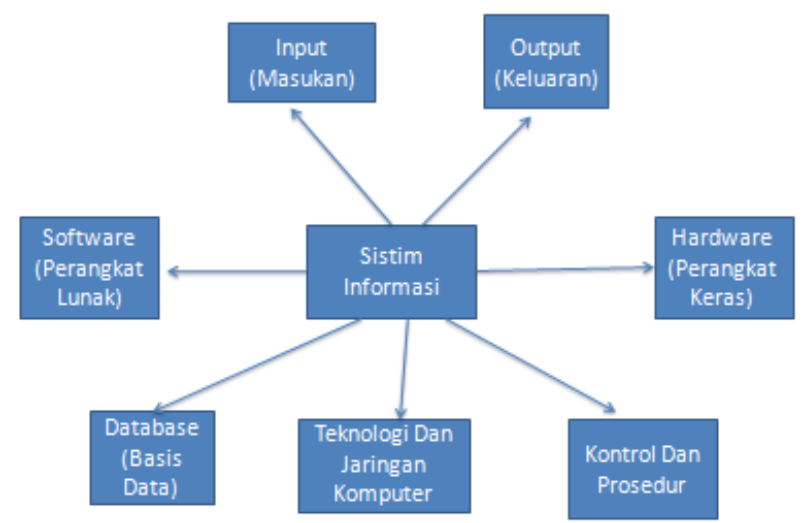

Gambar 2.1: Komponen-Komponen Dalam Sistem Informasi (Pratama, 2014)

\subsection{Unified Modelling Language (UML)}

Unified Modelling Language (UML) adalah salah satu standar bahasa yang digunakan di dunia industri untuk mendefenisikan requirement, membuat analisis dan desain, serta menggambarkan arsitektur dalam pemrograman berorientasi objek. Atau bisa diartikan sebagai salah satu alat bantu yang sangat handal di dunia pengembangan sistem yang berorientasi objek. Pada perkembangan teknologi perangkat lunak, diperlukan adanya bahasa yang digunakan untuk memodelkan perangkat lunak yang akan dibuat dan perlu adanya standarisasi agar orang diberbagai Negara dapat mengerti pemodelan perangkat lunak. Gambar berikut adalah unsur-unsur yang membentuk UML

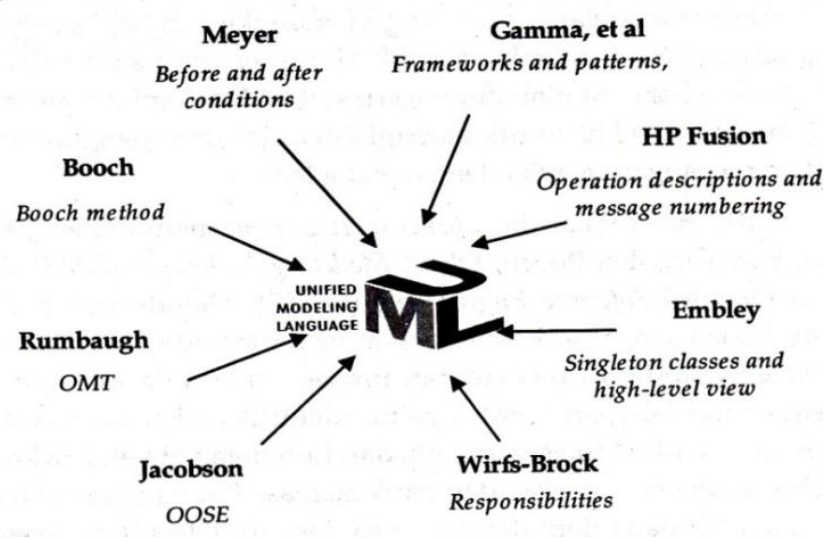

Gambar 2.2: Unsur-unsur pembentukan UML(Munawar, 2005)

\subsection{Customer Relationship Management}

Customer Relationship Management atau CRM adalah salah satu bentuk aplikasi Teknologi Informasi (TI) di departemen penjualan atau marketing suatu perusahaan, yang mendukung perusahaan untuk menyediakan pelayanan kepada pelanggan secara realtime dengan menjalin hubungan dengan tiap pelanggan yang berharga melalui penggunaan informasi tentang pelanggan.

Sasaran utama dari CRM adalah Untuk meningkatkan pertumbuhan jangka panjang dan profitabilitas perusahaan melalui pengertian yang lebih baik terhadap kebiasaan (bahavior) pelanggan. Sedangkan tujuan dari CRM adalah CRM bertujuan untuk menyediakan umpan balik yang lebih efektif dan integrasi yang lebih baik dengan pengendalian return on investment (ROI) diarea ini. 


\subsection{Pelanggan}

Pelanggan diartikan sebagai semua orang yang menuntut organisasi untuk memenuhi standar kualitas tertentu, dan karena itu memberikan pengaruh pada kinerja organisasi. Dalam hal ini terdapat tiga pemahaman tentang pelanggan, yaitu:

1. orang yang tidak tergantung pada perusahaan, tetapi sebaliknya.

2. orang yang membawa perusahaan untuk mengikuti keinginannya.

3. orang yang teramat penting yang harus dipuaskan.

\subsection{Personal Home Page (PHP)}

PHP adalah bahasa server side scripting yang menyatu dengan HTML untuk membuat halaman web yang dinamis. Maksud dari server-side scripting adalah sintaks dan perintah-perintah yang akan diberikan akan sepenuhnya dijalankan diserver tetapi disertakan pada dokumen HTML. Pembuatan web ini merupakan kombinasi antara PHP sendiri sebagai bahasa pemrograman dan HTML sebagai pembangun halaman web.

\subsection{Konsep Dasar Tentang Database MySQL}

MySQL dikembangkan sekitar tahun 1994 oleh perusahaan pengembang software dan konsultan database bernama MySQL AB yang bertempat di Swedia. MySQL adalah satu dari sekian banyak sistem database, merupakan terobosan solusi yang tepat dalam aplikasi database. Didukung oleh ribuan bahkan jutaan komunitas pengguna di internet yang siap membantu. MySQL adalah Relasional Database Management Sistem ( RDBMS ) yang didistribusikan secara gratis di bawah lisensi GPL ( General Public Lisensi), dimana setiap orang bebas menggunakan MySQL. MySQL sebenarnya merupakan turunan salah satu konsep utama dalam database sejak lama, yaitu SQL ( Structured Query Language ) yang merupakan sebuah konsep pengoperasian database, terutama untuk pemilihan / seleksi dan pemasukan data, yang memungkinkan pengoperasian data dikerjakan dengan mudah secara otomatis.

\section{METODOLOGI}

\subsection{Analisa Sistem}

Dalam mengatasi setiap permasalahan, sebelum menuju ke sasaran atau tujuan yang diinginkan, maka perlu dilakukan analisa terhadap permasalahan yang sebenarnya.Analisa sistem dapat didefenisikan sebagai penguraian dari suatu sistem yang utuh ke dalam bagian komponennya dengan maksud untuk mengidentifikasi dan mengevaluasi permasalahan, hambatan yang terjadi dan kebutuhan yang diharapkan sehingga dapat diusulkan perbaikannya.

\subsection{Aliran Sistem yang Sedang Berjalan}

Analisa sistem yang sedang berjalan dilakukan guna untuk mengetahui permasalahan yang sedang dihadapai dalam sistem informasi penjualan produk. Adapun sistem yang sedang berjalan pada Toko Lusi Ana Gorden.

1. Customer atau pelanggan datang keToko Lusi Ana Gorden, dan melihat barang, serta melakukan pembelian.

2. KasirToko Lusi Ana Gordenmembuat bukti pembayaran serta mencatat transaksi penjualan, setelah itu bukti diberikan kepada pembeli.

3. Kemudian kasir membuat laporan penjualan dan menyerahkan kepada pimpinan.

Input dari sistem merupakan dokumen yang digunakan dalam proses transaksi diantaranyafatktur penjualan barang. Data-data ini yang nantinya akan diolah dalam merancang sistem informasi penjualan dan promsosi berbasis website pada Toko Lusi Ana Gorden. Analisa yang dilakukan terhadap proses dalam pengolahan data penjualan produk menunjukan bahwa toko ini belum memakai suatu aplikasi sistem infomasi atau program, sehingga dalam pengolahan data penjualan produk yang masih dilakukan menggunakan aplikasi Microsoft Excel. 
Berdasarkan analisa yang dilakukan terhadap output sistem yang sedang berjalan padaToko Lusi Ana Gordendapat dilihat bahwa sistem yang sedang berjalan belum mampu menghasilkan informasi-informasi dan laporan-laporan yang dibutuhkan dengan baik.

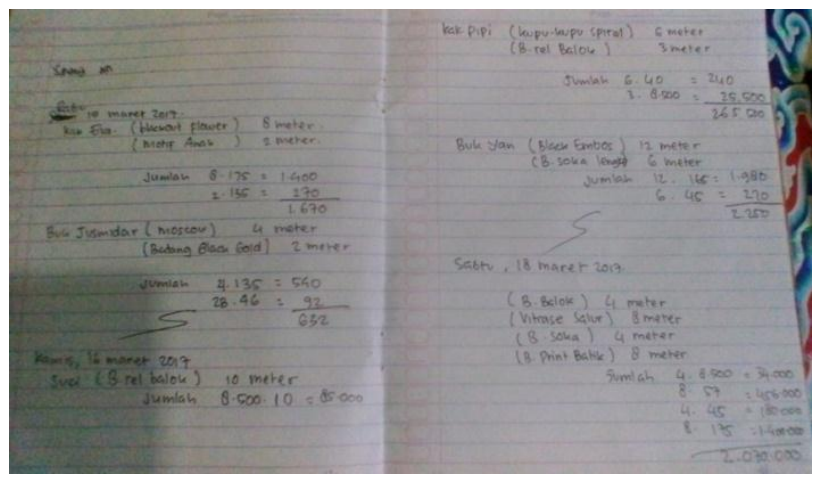

Sumber :Toko Lusi Ana Gorden

Gambar 3.1Laporan Pemesanan

Untuk mengatasi masalah yang dihadapi oleh sistem lama maka dibentuklah sistem baru berbasis website.Dimana proses pembelian dapat dilakukan oleh pembeli hanya dengan menggunakan jaringan internet sehingga pembeli tidak perlu datang ke Toko Lusi Ana Gordensehingga memberikan kemudahan kepada pembeli dan dapat menghemat waktu pembeli. Tujuan dari desain sistem adalah untuk meningkatkan penjualan dan pendapatan serta meminimalkan biaya yang dikeluarkan untuk promosi dalam penjualan barang, perincian-perincian yang mudah dipahami sehingga tidak terjadi kesalahan dalam menjalankan sistem. Desain sistem pada hakekatnya bukanlah sekedar mempercepat atau mengoptimalisasikan kegiatan operasi tapi juga mencakup standarisasi dengan hasil dalam penghematan waktu dan biaya. Desain global atau yang sering disebut desain makro sistem merupakan desain yang mengambarkan atau memberikan gambaran secara umum kepada user tentang sistem yang akan dibangun dan informasi-informasi apa saja yang akan dihasilkan dari sistem baru yang dibangun

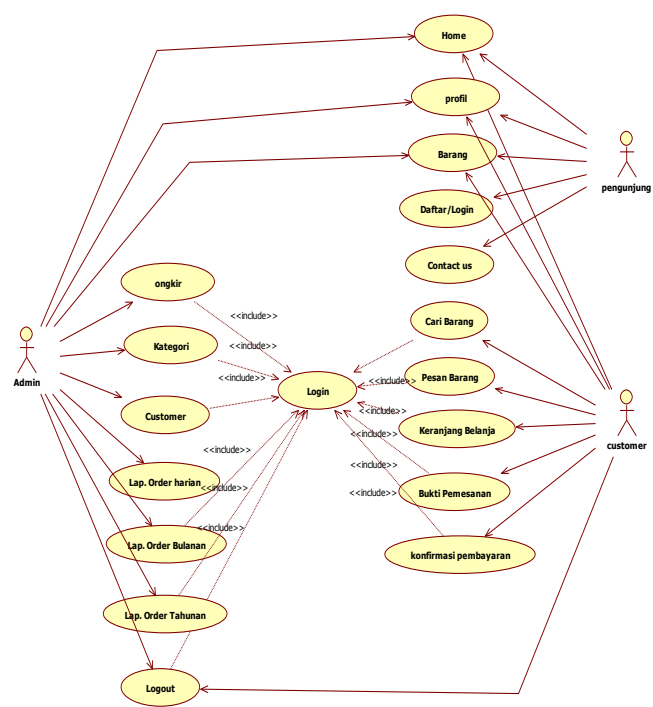

Gambar 3.2Use Case Diagram 


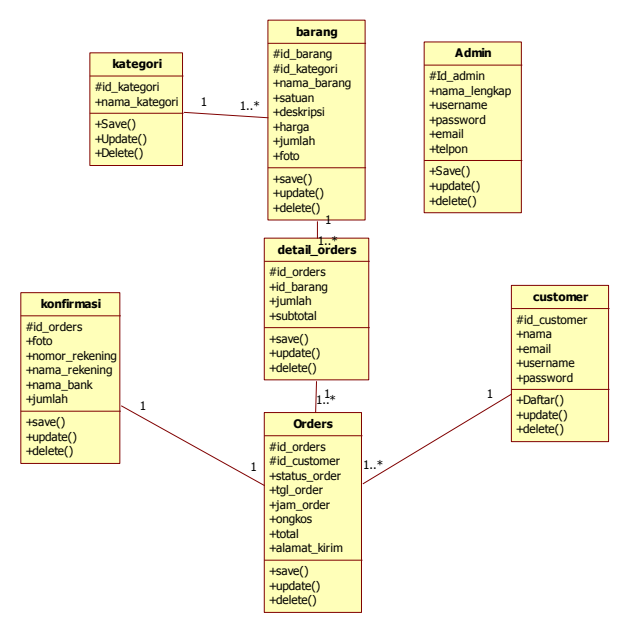

Gambar 3.3Class Diagram

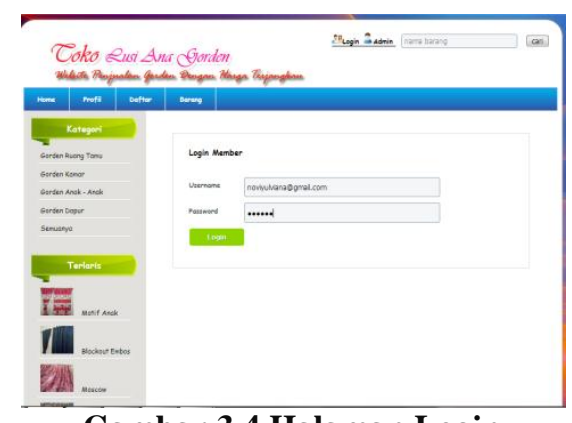

\section{KESIMPULAN}

Gambar 3.4 Halaman Login

Berdasarkan perancangan Sistem pemesanan barang secara online pada Toko Lusi Ana Gorden, yaitu:

1. Dengan adanya sistem informasi pemesanan barang secara online pada toko Lusi Ana Gorden proses pemesanan barang menjadi lebih efesien.

2. Dengan implementasi Sistem Informasi pemesanan barang secara online pada toko Lusi Ana Gorden dapat menghindari terjadinya kesalahan dalam menyimpan data pelanggan.

3. Sistem informasi pemesanan barang ini dapat melakukan pengolahan data laporan dengan mudah dan mempermudah cara kerja dalam perhitungan jumlah pemesanan pada toko Lusi Ana Gorden.

4. Sistem informasi pemesanan barang ini dapat memperluas ruang lingkup pemesanan barang kepada pelanggan, sehingga pangsa pasar menjadi lebih luas.

5. Aplikasi berbasis web ini mampu untuk memaksimalkan pemesanan dan meningkatkan keuntungan.

Setelah beberapa kesimpulan yang dikemukakan oleh penulis terhadap perancangan sistem informasi pemesanan barang yang baru, ada beberapa saran yang yang sebaiknya dilakukan oleh toko Lusi Ana Gorden adalah:

1. Dalam penerapan sistem pemesanan barang pada toko Lusi Ana Gorden sebaiknya didukung oleh perangkat yang cukup memadai baik dari segi manusia (brainware) maupun dari segi peralatan perangkat kerasnya (hardware system) dan sistem pemesanan barang pada toko Lusi Ana Gorden yang baru juga perlu dilakukan pemeliharaan atau perawatan terhadap sistem tersebut.

2. Memberikan pengetahuan terhadap pemakai sistem dalam menggunakan sistem yang baru. 
3. Selanjutnya dalam penerapan sistem informasi baru agar pengolahan data pemesanan kebaya dapat memberikan informasi sebagaimana yang diharapkan, sebaiknya diciptakan sistem kerja yang teratur pada masing-masing bagian pada toko Lusi Ana Gorden ini.

4. Agar data-data pemesanan barang tidak mengalami lost of data (kehilangan data) hendaknya sekali dalam sebulan dibuatkan backup data dari database ke dalam drive lainnya.

\section{DAFTAR PUSTAKA}

Khuzaeva A.S (2014), "Mengembangkan Pola Pikir Cerdas, Kreatif dan Mandiri melalui Telematika", Jurnal Lingkar Widyaiswara, Vol. 1, No. 4, hal. 138-148.

Musanto T (2004), "Faktor-faktor Kepuasan Pelanggan dan Loyalitas Pelanggan: Studi Kasus pada CV. Sarana Media Advertising Surabaya”, Jurnal Ekonomi Manajeme Fakultas Ekonomi Universitas Kristen Petra, Vol. 6, No. 2, hal. 123-136.

Indrajani (2015), “Database Design”, Jakarta : Elek Media Komputindo.

Jogiyanto HM (2008), "Analisa Dan Desain Sistem Informasi", Yogyakarta : Andi Ofset.

Pratama, I Putu Eka, (2014), “Sistem Informasi Dan Implementasi”, Bandung : informatika. 